\title{
Instilling safety culture in the passenger rail transport industry within the South African context
}

\author{
Authors: \\ Khulumane J. Maluleke ${ }^{1}$ \\ Affiliations: \\ ${ }^{1}$ Department of Transport \\ Economics, Logistics and \\ Tourism University of \\ South Africa \\ Correspondence to: \\ Khulumane Maluleke \\ Email: \\ johnm@infraafricaholdings. \\ co.za \\ Postal address: \\ PO Box 1237, Pretoria 0001 \\ South Africa

\section{Dates:} \\ Received: 03 Dec. 2012 \\ Accepted: 03 June 2013 \\ Published: 15 July 2013 \\ How to cite this article: \\ Maluleke, K.J., 2013 , \\ Instilling safety culture in \\ the passenger rail transport \\ industry within the South \\ African context', Journal of \\ Transport and Supply Chain \\ Management, 7(1), Art. \\ \#84, 6 pages. http://dx.doi. \\ org/10.4102/jtscm.v7i1.84

\section{Copyright:} \\ (C) 2013. The Authors. \\ Licensee: AOSIS \\ OpenJournals. This work \\ is licensed under the \\ Creative Commons \\ Attribution License.
}

Read online:
South Africa has two major rail operators that constitute the rail transport industry. These are Transnet Freight Rail (TFR), which operates freight and the Passenger Rail Agency of South Africa (PRASA). Although the Railway Safety Regulator (2011:29) reported the year on year declining trend of collisions, the main concern is that the costs incurred for each year's incidents is escalating. This article is concerned with the declining safety standards of these operators as evidenced by 742 collisions recorded during the $2011 / 2012$ financial year for both operators. The focus is mainly on collisions during the movement of rolling stock within the PRASA environment. The analysis of the occurrences is narrowed down, with the emphasis on the province of Gauteng. In the analysis of the causes of these collisions, the problems that led to the root causes of these collisions is reported. Of critical importance is that every transport operator is faced with the challenges of how to effectively respond to the basic transport needs and requirements of the travelling public. The transport users' need is to travel between the two geographical points. During the journey between these geographical points, the operator has safety and security requirements and must provide a reliable, accessible and affordable transport system. As the travelling public becomes more affluent, the transport needs become open ended and require much more rational public choices. The rail transport system remains a vital or indispensable business sector of the economy. By investing in new technology, rolling stock and infrastructure, we woud see an increase in innovation, competitiveness, and an elevated standard of living.

\section{Introduction}

Currently, the South African passenger rail transport industry is working hard to decrease failures and incidents on its network. It also continues to channel investments towards the refurbishment of its rail infrastructure. There are two major rail operators that constitute the rail transport industry: Transnet Freight Rail (TFR), which transports freight, and the Passenger Rail Agency of South Africa (PRASA), which transports passengers. This research focuses on PRASA and strives to analyse the causes of incidents within its environment. Although the Railway Safety Regulator (2011:29) reported the year on year declining trend of collisions with 742 incidents reported during the 2011/2012 financial year, the main concern is that the costs incurred for each year's incidents is escalating. For example, Figure 1 shows the declining trend of incidents year on year, whilst Table 1, supported by Figure 2, shows an escalation of costs year on year. The financial years of 2008/2009/2010/2011/2012 had escalating costs of R3.5 million, R21.9 m, $\mathrm{R} 24.4 \mathrm{~m}$ and $\mathrm{R} 61 \mathrm{~m}$ respectively.

If the concept of safety is not given the attention and priority it deserves, passenger rail transport will be viewed as a catalyst for economic depression, non-productivity and unemployment rather than a catalyst for economic development. This is so because when an accident occurs, the disruption disturbs the timeous arrival of people, goods and services and impacts negatively on employment and the economy. In order to unearth the root cause of a series of accidents that took place within the Province of Gauteng between 2008 and 2012, this study looked at whether the actions preceeding these accidents had any deliberate deviations from the prescribed standard operating procedures. If an accident is as a result of the intended outcome, then this may be referred to as 'some kind of violation' (Reason 2008:30).

\section{Purpose of the article}

The purpose of this article is to explore the extent to which human error contributes to fatal accidents, injury to the commuting public and loss to PRASA. The predominant focus is on accidents and human error as they are considered to be the major contributing factors. It is important to note that it is not the intention of this research to expose or blame any of the Rail Operating Companies' inefficiencies. 


\section{Hypotheses generation}

Hypothesis 1: Accidents are a result of obsolete and malfunctioning signalling systems.

Hypothesis 2: The standard operating procedures are not clear and specific enough.

Hypothesis 3: Human error causes accidents due to noncompliance with the operating communication procedures.

\section{Research strategy}

This research study seeks to explore and present ways of managing and maintaining an incident-free passenger rail transport system in South Africa. It is believed that a

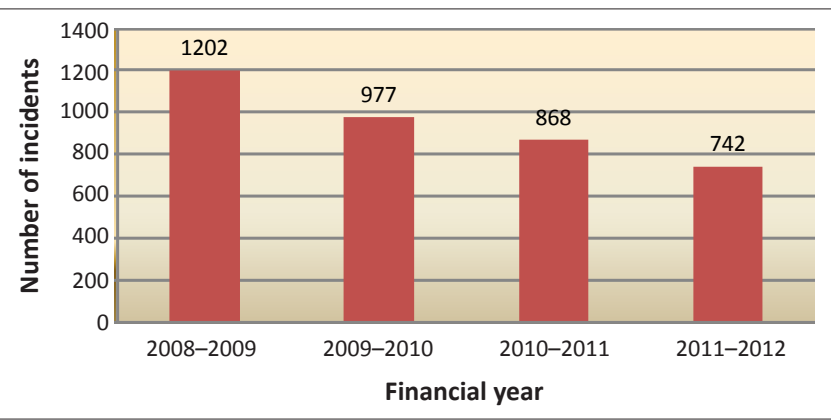

Source: Adapted from Railway Safety Regulator, 2011, South African Railway State of Safety Report 2011/2012, p. 29

FIGURE 1: Number of year on year incidents.

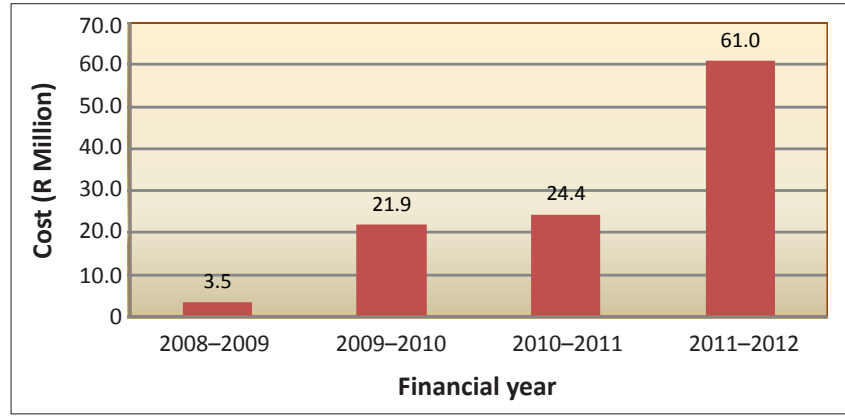

Source: Adapted from Railway Safety Regulator, 2011, South African Railway State of Safety Report 2011/2012, p. 18

FIGURE 2: PRASA: Costs incurred with respect to collisions.

TABLE 1: Annual costs in R million incurred by PRASA.

\begin{tabular}{ll}
\hline Description & Collisions \\
\hline $2008 / 09$ & 3.5 \\
$2009 / 10$ & 21.9 \\
$2010 / 11$ & 24.4 \\
$2011 / 12$ & 61.0 \\
\hline
\end{tabular}

Source: Adapted from Railway Safety Regulator, 2011, South African Railway State of Safety Report 2011/2012 quality passenger rail transport service would culminate in a sustainable competitive advantage over other modes of transport, particularly when safety is instilled as a culture in the operation of the entire passenger rail transport system. The researcher drew data from various sources, ranging from newspapers, safety research reports, text books, personal observation and informal interviews with individual offduty train drivers.

\section{Discussion}

\section{A theoretical perspective of risk management}

Whether the transport operating entity is large or small, it is not unreasonable to expect that there will be a crisis looming some time in future as there is always an element of uncertainty; no transport operator or industry can be considered to be immune. The fact that PRASA is most often caught up in an array of disruptions and incidents every year should not be seen as an unusual situation because it must be accepted that disruptions can occur anytime and there has to be a mechanism in place to manage and maintain the risk.

If the Passenger Rail Agency is to provide a high quality service with safety as an embedded culture, a risk management approach is needed, as quoted from the advice of Kildow where it is stated:

If we agree that disasters are inevitable, it would seem logical that we must also agree that it is wise to take the necessary steps to manage our risks to the extent possible and to reduce the effects of disruptions through planning and preparedness (2011:xvii).

In the Gauteng Province, some of the types of incidents that took place between 2011 and 2012 were related to rear end collisions. The total amount lost by PRASA as a result of these collisions amounted to R52.40 m.

\section{Testing of hypotheses}

Hypothesis 1: Accidents are a result of obsolete and malfunctioning signalling systems.

It is evident that the accident that occurred on 08 April 2011 at Winternest cannot be said to have been caused by 'obsolete and malfunctioning of the signalling system' because the driver passed the signal at danger prior to the collision. For the purpose of this study, Hypothesis 1 cannot be said to be valid as human error appears to have been the overriding reason for the collision.

Hypothesis 2: The standard operating procedures are not clear and specific enough.

TABLE 2: Gauteng Province selected incidents location and amount lost.

\begin{tabular}{llll}
\hline Date of occurrence & Type of incident & Location of loss & Loss amount (R million) \\
\hline 2011 April 08 & Rear end collision & Winternest & R16.40 \\
2011 May 19 & Rear end collision & Mzimhlope & R28.00 \\
2012 February 04 & Rear end collision & Soshanguve & R8.00 \\
\hline Total & - & - & R52.40 \\
\hline
\end{tabular}

Source: Adapted from Railway Safety Regulator, 2011, South African Railway State of Safety Report 2011/2012 
Train operations have many specific standard train operating procedures that must be followed. The analysis of why these incidents occurred cannot be attributed to these procedures not being clear and specific enough; the human element remains the root cause of the incidents. It is therefore clear that Hypothesis 2 cannot be said to be absolutely valid.

Hypothesis 3: Human error causes accidents due to noncompliance with the operating communication procedures.

It is apparent that the root cause of these incidents involved human error as evidenced by the Railway Safety Regulator (2011:x), it states 'Collisions are as a result of non-compliance with the operating communication procedures during train operations because of human error'. This empirical evidence therefore renders Hypothesis 3 valid.

There is therefore a need to review the regulatory safety procedures to ensure that the safety of PRASA is given the attention it deserves. This can be achieved by cultivating a culture of safety, business continuity and a favourable difference between life and death.

The management of risk in any human endeavour requires careful and objective consideration within the environment in which one operates. This should be the case with regard to PRASA's train operation environment. It should be noted that the risk management process begins with understanding the elements of the transport system, identifying, assessing and managing the associated risk factors throughout the entire passenger rail transport system value chain.

\section{The concept of safety as a means of managing risk}

The concept of safety includes a notion of hazard. Whether one is talking about safety as a situation, a feeling or a practice, we are always talking about being safe from something. When talking and writing about safety, there will always be a need to specify the types of incidents involved. The type of safety in this case relates to train operations being safe from collisions and derailments. This type of event can be specified into major accidents, which involve human and financial losses and injuries to passengers.

Accidents often occur because of an accumulation of mistakes caused by train operating staff. Reason (2008:37) was of the view that mistakes are often difficult and sometimes impossible to discover because we do not necessarily know the ideal pathway towards an intended goal. Not achieving the desired outcome does not in itself signal a mistake. It is common that errors can take the form of systematic 'absent minded' action slips and memory lapses.

\section{The Concept of Culture and safety}

Teegarden, Hinden and Sturm (2011:8) viewed culture as 'the totality of socially transmitted behaviour patterns, arts beliefs, institutions, and all other products of human work and characteristics of a community or population'. This research reviews culture and safety together, and refers to it as 'safety culture'. It means that safety should manifest itself as a totality; instilled, transmitted and demonstrated throughout all organisational human work. Within PRASA, safety should be demonstrated throughout the entire organisation and should not be only confined to safetycritical and safety-related grades.

The concept of safety culture should be ingrained in the deepest, unconscious aspects of all departments of PRASA. It should be turned into a tangible concept and needs to touch every person within the organisation, and should influence the way in which people relate to one another.

This research adopts the assumption that 'accidents are mainly caused by human error or failure' (Antonsen 2009:9). According to this reasoning, a safety-conscious organisation can be designed by creating a management system that specifies objectives, distributes responsibility, plans, organises and controls according to safety precautions. PRASA should therefore ensure that human error is given attention throughout the entire organisationa.

\section{A theoretical perspective of safety culture}

Antonsen (2009:12) draws an analogy between the buildup of accident occurrence probability and the outbreak of a disease, since they both seem to progress through a phase of incubation. When PRASA finds itself in an incubation phase it needs to take cognisance of every hazard occurring within the organisation. The incubation phase is reached when there are difficulties with transmission of information - this results in communication breakdown, which eventually generates the accident.

Operating in a normal situation: Keyton (2011:8), was of the view that an organisation is in a normal situation when it is at a stage where it is dynamic and responsive to the market and adheres to the regulatory environment. The market environment of PRASA refers to passengers and the regulatory environment is represented by the Railway Safety Regulator. It is at this stage where a considerable amount of intensive communication with respect to safety culture has to take place within and across departments of the entire PRASA.

Keyton (2011:10) further argued that 'everything an organization does is done through its members who process and communicate information from both internal and external sources. PRASA need to ensure that its institutional memory is sustained by preserving safety culture knowledge, behaviours, norms, and values over time'.

Operating at the incubation phase: This implies that that there will be signs or symptoms that things are about to go wrong before the onset of the crisis. An example would be repeated violations of procedures as symptoms of an organisation being in a state of incubating an accident. When this happens to an organisation such as PRASA, the logical step would be to detect the danger signals and to start 
instilling an appropriate safety culture. The primary mission of analysing the incubation period is to assess how errors develop towards the trigger point. The incubation phase ends when the different latent factors coincide to create the event that triggers the disaster. This way of viewing accidents as created by the occurrence of latent conditions and active failures has been highly influential for later accident models as shown in Figure 3.

Reaching the trigger event in operation: Rausand (2011:68) defined a trigger event as a condition that builds up and thus causes a hazard, which gives rise to an accident. For PRASA to provide a high quality service, it would be advisable to adopt a considerable degree of reliability as a user requirement, where the safety levels are elevated and measured in terms of Million Passenger Kilometres (Railway Safety Regulator 2011).

Emerging crisis: Proponents of high-reliability organisations are of the view that cultural aspects play a fundamental role in maintaining safety. Culture is viewed as an important informal co-ordination mechanism, which can constitute an alternative to the structural centralisation concentrated at the corporate level of an organisation. This is also viewed as a way of dealing with the risks connected with extremely complex and tightly-bound organisations and technologies. In addition to instilling safety culture, an organisation like PRASA needs to cultivate the safety climate, which is referred by Antonsen, as a situation:

... where managers at all levels are highly committed to safety, where the workforce express satisfaction with and adherence to the organisation's safety system, where everyone is risk averse, where there is no pressure towards maximising profits at the expense of safety and where operators as well as managers are highly qualified and competent (2009:17).

Rescue, crisis management: The United Nations Human Settlements Programme (2007:167) asserted that an entity is said to be in a crisis situation when life support systems fail in the face of pressure from external stress, resulting in loss of life, damage to property and the undermining of livelihoods. This situation is reached when an accident occurs and the focus is on rescuing those who are trapped. Given the extreme challenges the PRASA train drivers face in their work environment due to systems failures, an intervention is sought to normalise the operation.

Antonsen (2009:15), argued that organisations that value case studies about past safety issues are more reliable in the competitive landscape. PRASA should consider holding symposiums where case studies are presented as evidence of how safety regulations and procedures can be implemented at the accident scene. In this way the communication of safety-critical knowledge throughout the entire passenger rail industry is indispensable as this would strive to restore the safe operations and thus promote the safety culture. This could be done by bringing back retired employees who would disseminate safety cultural stories amongst the train operating staff.
Cultural adjustment: Keyton (2011:10) advised that for cultural adjustment to take place there has to be several streams of communication through multiple channels in multiple contexts. Safety cultural diffusion should be encouraged; ranging from informal communication, such as a guest speaker, to extremely advanced formal communication, such as a safety conference.

For PRASA to undergo cultural adjustment and revert to a normal operating situation, it has to operate as a flexible, interactional system, which is composed of layers of ongoing conversations about safety culture. When information is shared amongst organisational members and codified in some way, an organisational interpretation will exist beyond that of its individual members. These interpretations will get passed from employee to employee, creating what is referred to as 'thread of coherence' (Keyton 2011:10) even though there may not be full convergence. The interactions of individuals create an organisational-level interpretation that can be passed on to others. Operating in the normal situation can be sustained by a holistic application of safety climate and culture.

The increased interest in the relationship between culture and safety is associated with a shift in the way we think about how organisations are created, managed and how they function. The classical view of organisations rests on an assumption that organisations and their members act according to rational principles.

\section{Instilling safety culture and organisational culture}

Antonsen (2011:16), defined safety culture as 'The product of individual and group values, attitudes, perceptions, competencies, and patterns of behaviour that determine the commitment to, and the style and proficiency of, an organisation's health and safety management'. The concept is often viewed by safety scientists as a subset of organisational culture or as those parts of organisational culture that influence safety. Having unearthed the importance of safety

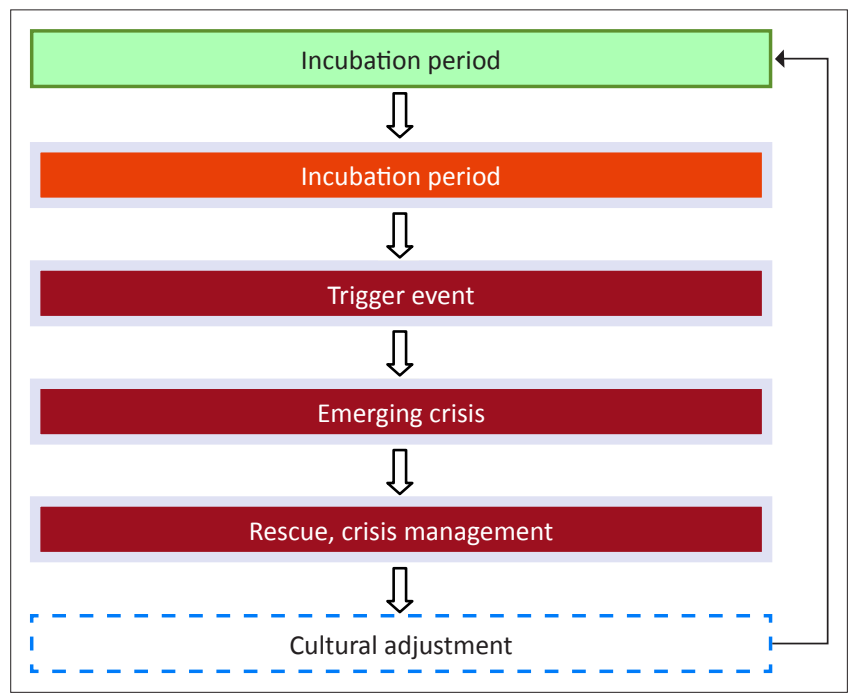

FIGURE 3: Accident investigation model. 
culture within the organisational context of PRASA, the main goal is to ensure that all members' understanding of the concept is deepened.

\section{Organisational culture}

Teegarden et al. on the one hand viewed human culture as something that emerges from people's struggles to manage uncertainties and create some degree of order, whilst Keyton, on the other hand, defines organisational culture as:

... a pattern of shared basic assumptions that was learned by a group as it solved its problems of external adaptation and internal integration, that has worked well enough to be considered valid and, therefore, to be taught to new members as the correct way to perceive, think, and feel in relation to those problems (2011:19).

In his book, Tang (2011:9) argued that if one has to effect institutional change, the source of change must be endogenous. Derived from this wisdom, it would be advisable for the passenger rail transport industry to ensure that the source of the safety culture be from within and should be communicated effectively to reach the targeted audience. Effective communication would render a dynamic safety culture, as it is not fixed or tied to a specific physical location or to a specific collection of people.

\section{Artefacts}

Safety culture can be promoted through the use of artefacts. Artefacts are visible, tangible objects that can be seen, heard or felt within the organisational experience. They are often the first things that are noticeable when entering an organisation's premises. The display of an organisation's safety standards and norms would constitute appropriate artefacts that promote safety culture, just like the more physical attributes of organisational life. Often the first artefact associated with an organisation is its logo. Not only does a logo indicate the presence of the organisation, but it also distinguishes it from other organisations. Artefacts are derived from symbols and as such, are the basis of organisational culture (Keyton 2011:22). The passenger rail transport industry should strive to display safety-related artefacts where they can be seen by organisational members and the travelling public.

\section{Values}

A value is a broad tendency to prefer certain states of affairs over others and determines our view of reality. Values are strategies, goals, principles, or qualities that are considered to be ideal. The values of an organisation are often visible in the actions of its employees, and they influence how organisational members facilitate and practice communication. Keyton (2011:24) stressed that values must be phrased in a positive way, making it difficult for someone to disagree. For example, if the passenger rail transport industry stressed safety as 'The First Consideration', as it used to be in the past, this would rekindle the memory of safety culture and no one would want to disagree with this value statement.

\section{Assumptions}

Safety matters should drive organisational members from within and should be deeply entrenched throughout all levels of the organisation. Organisational members can hold assumptions about themselves or about their relationships with other organisational members with respect to the work they perform. For the safety culture to be promoted, the passenger rail transport industry should consider encouraging the adoption of assumptions, as this would help to guide behaviour by directing how organisational members should perceive, think, feel and act (Keyton 2011:27).

\section{Effective organisational communication}

Without effective communication, an organisation cannot respond to the concerns of its customers or clients. It is a fact that organisations cannot exist without effective communication. Even before the members are communicating with potential customers and clients, they must communicate with one another to create and develop the organisation's safety climate and culture (Keyton 2011:11).

\section{Conclusion}

It can be concluded that amongst the root causes of train collisions that have been investigated, Hypotheses 1 and 2 cannot be construed to be the root causes. Empirical evidence points out that Hypothesis 3, which states that 'Collisions are as a result of non-compliance with the operating communication procedures during train operations because of human error', appears to be appropriate. If the safety culture is promoted within the passenger rail transport industry in South Africa, the business of transport may become more vibrant; without it, neither the economy nor society can function.

\section{Recommendations that are of critical importance}

Bearing in mind that a recommendation may require a substantial amount of money in order for it to be implemented, it is advised that the fiscal allocation for the execution of rail transport infrastructure programmes are R11.2 billion, R14.6 b, R18.02 b for the 2013-2016 Medium Term Expenditure Frameworks respectively (National Expenditure Estimates 2013:904). The authors recommendations are:

- Consider exploring more advanced Automatic identification systems (AIS) in the passenger rail transport industry. This would serve as a new technological intervention to assist drivers in their daily operations.

- Safety should be demonstrated throughout all organisational human work and should not be confined to safety-critical and safety-related grades only.

- Effective communication within and across departments should form a favourable stimulus to unleash safety cultural diffusion within the entire organisation.

In conclusion, it is of fundamental importance that safety culture be instilled and engineered amongst the total work force, in order to improve safety of the passenger rail transport industry in South Africa. 
For safety climate and culture to be sustained there has to be improvement by means of:

- Developing safer machines and equipment.

- Increasing focus on improving safety through strategic recruitment.

- Upgrading employees' technical skills.

- Making efforts to increase employee motivation by improving work at the individual level.

\section{Acknowledgements}

\section{Competing interests}

The author declares that he has no financial or personal relationship(s) that may have inappropriately influenced him in writing this article.

\section{References}

Antonsen, S., 2009, Safety culture: Theory, method and improvement, Ashgate, Great Britain.

Grigg, N.S, 2010, Infrastructure Finance: The business of infrastructure for a sustainable future, John Wiley \& Sons, New Jersey. http://dx.doi.org/10.1002/9781118266182

Keyton, J., 2011, Communication and Organisational Culture: A key to understanding work experiences, SAGE, London. PMid:23223093, PMCid:PMC3513779

Kildow, B.A., 2011, Supply chain management: Guide to business continuity, AMACOM, New York.

Rausand, M., 2011, Risk Assessment Theory, Methods, and Applications, John Wiley, New Jersey.

Reason, J., 2008, The Human Contribution Unsafe Acts, Accidents and Heroic Recoveries, Ashgate Publishing Company, Burlington.

Railway Safety Regulator, 2011, South African Railway State of Safety Report 2011/2012.

Teegarden, P.G., Hinden, D.R. \& Sturm, P., 2011, The Nonprofit Organizational Culture Guide: Revealing the hidden truths that impact performance, Jossey-Bass, San Francisco. 